\title{
The older adult with a spinal cord injury
}

\author{
E J Roth MD, L Lovell, A W Heinemann PhD, M Y Lee MD, G M Yarkony MD
}

Midwest Regional Spinal Cord Injury Care System, Northwestern University Medical School, Rehabilitation Institute of Chicago, Chicago, Illinois 60611, USA.

\begin{abstract}
Sixty-two consecutive acute spinal cord injury (SCI) patients who were aged 55 years or older were studied and compared to 296 SCI patients of age less than 55 years. Compared to younger patients, the older group had significantly more females $(29 \%)$, preexisting medical conditions $(87 \%)$, associated injuries $(55 \%)$, incomplete quadriplegic patients $(63 \%)$, and persons whose injuries resulted from falls $(53 \%)$. There were no differences between groups in frequency of ventilator use, occurrence of medical complications, or acute length of stay, but older patients tended to have fewer surgical spinal fusions (40\%), shorter rehabilitation stays (66.5 days), more indwelling urethral cathteters $(31 \%)$, and more nursing home discharges $(19 \%)$. With other factors being controlled, advancing age was predictive only of nursing home discharge, and not of acute or rehabilitation lengths of stay. Among older SCI patients, those with complete injuries were nearly 3 times as likely to have been discharged to nursing homes in our series compared to older patients with incomplete lesions. Although many aspects of the presentation, course, and care of older SCI individuals are similar to those of younger patients, there are several unique features of older adults with a SCI.
\end{abstract}

Key words: spinal cord injury; paraplegia; quadriplegia; rehabilitation; older adults; geriatrics.

\section{Introduction}

Geriatric trauma is a major public health problem in the United States. Approximately 29 million persons in the US, or $11 \%$ of the population, are 65 years of age or older. ${ }^{1}$ Unintentional injuries of persons in this age group account for about 24,500 deaths $^{2}$ and about 816,000 hospitalizations each year in the US. ${ }^{3}$ Compared to younger trauma victims, older individuals have a greater fatality rate, longer length of hospitalization, greater frequency of complications, and greater costs of care.$^{4-10}$ Despite these figures, most trauma research has focused on injury in the young. ${ }^{9}$

One of the most serious of all trauma types, spinal cord injury (SCI), has traditionally been identified as a condition of youth. However, as many as $20 \%$ of all spinal cord injuries occurs in persons of age 65 years or older. ${ }^{11,12}$ With an estimated incidence rate of 11 per 100,000 older adults per year, the frequency of SCI in this group is equal to or greater than that of any other age group. ${ }^{11}$

Only a limited number of reports exist on the subject of SCI in the elderly; most of these suggest that there are significant differences between older and younger patients. It has been reported that the group of older adults with SCI includes proportionately more females than does the younger group. ${ }^{13.14}$ Among older patients, falls have been reported to be the usual cause, and incomplete quadriplegia the most common presentation. ${ }^{13-15}$ Older adults also have been found to have a significantly greater incidence of complications, unfavorable discharge placements, ${ }^{14,16,17}$ and death after SCI. ${ }^{12,14.16 .18-24}$ Two studies have suggested that prognosis for functional independence is age related, ${ }^{17.25}$ while a recent study of 708 SCI patients reported age to have little influence on functional outcome. ${ }^{15}$

Because older adults represent a significant segment of the group of patients with 
$\mathrm{SCI}$, and their care needs are unique, ${ }^{26}$ the present study was undertaken to describe more comprehensively some characteristics of this special population. The purposes of the present investigation were (1) to study the demographic, injury, and outcome characteristics of older adults who sustain a $\mathrm{SCI}$; (2) to compare those characteristics with those of younger SCI patients; and (3) for the older patients, to determine associations between demographic and injury characteristics and their outcomes.

\section{Methods}

\section{Patients}

The study sample consisted of all consecutive patients with acute traumatic SCI admitted to the Rehabilitation Institute of Chicago for initial comprehensive inpatient interdisciplinary rehabilitation between 1 January 1986 and 31 December 1988. All patients who were disabled by the injury and who had the cognitive ability to participate in the rehabilitation program were included; only patients in whom dementia was so severe that they could not participate in the rehabilitation program were excluded.

There was a total of 358 SCI patients, including $62(17 \%)$ who were aged 55 years or older and $39(11 \%)$ who were aged 65 years or older. Although geriatric patients are generally considered to be of age 65 years or older, those who were 55 years or older were referred to as 'older adults' for the purposes of this study.

\section{Procedures}

The complete medical records of each patient were reviewed and the following information was documented: preinjury variables-age; gender, and preexisting condition (defined as any medical problem occurring prior to $\mathrm{SCI}$ ); injury variables - neurological class (level and completeness of SCI), etiology of SCI, associated injury, surgical spinal fusion (performed for acute spinal instability), ventilator use following SCI, medical complication (defined as any condition occurring after the SCI which required medical intervention, such as infection, cardiopulmonary disorder, or muscu- loskeletal problem), and urinary bladder management; and outcome variablesacute length of stay, rehabilitation length of stay, and discharge location.

\section{Data analysis}

Patients were divided into 2 groups on the basis of age; the 'younger' group consisted of the 296 patients who were under 55 years old and the 'older' group of the 62 patients who were 55 years old or over. Differences in categorical data between older and younger SCI patients were determined using $\mathrm{X}^{2}$ analysis. Differences in continuous data (acute and rehabilitation length of stay) between older and younger SCI patients were determined using Student's t-test. Predictors of each outcome variable were determined using multivariate analysis of variance, with preinjury and injury data as independent variables, and age as a covariate.

Separate analyses were conducted using data from the older age group alone. Means for acute length of stay and rehabilitation length of stay were compared between groups classified on the basis of preinjury and injury variables using Student's t-test. In addition, discharge location distribution was compared between groups classified on the basis of preinjury and injury variables using $\underline{X}^{2}$ analysis.

\section{Results}

\section{Sample characteristics}

The mean $( \pm$ SD) age of the study sample was $35.0 \pm 17.5$ years. There were 296 $(83 \%)$ patients who were under 55 years old and $62(17 \%)$ patients who were 55 years old or older. The sample consisted of 292 $(82 \%)$ males. Slightly more than one half (180) of the patients had one or more of the preexisting medical conditions listed in Table I. The mean ( \pm SD) number of preexisting conditions was $0.9 \pm 1.1$.

Sixty-two patients $(17 \%)$ had complete quadriplegia, $143(40 \%)$ sustained incomplete quadriplegia, $80(22 \%)$ had complete paraplegia, and $73(21 \%)$ incomplete paraplegia. Injuries resulted from road traffic accidents in $128(36 \%)$ patients, from falls in 
Table I Preexisting medical conditions

\begin{tabular}{lcc}
\hline Condition & $\begin{array}{c}\text { Younger } \\
\mathrm{N}=296\end{array}$ & $\begin{array}{c}\text { Older } \\
\mathrm{N}=62\end{array}$ \\
\hline Ethanol abuse & $89(30 \%)$ & $19(31 \%)$ \\
Drug abuse & $48(16 \%)$ & $4(6 \%)$ \\
Hypertension & $12(4 \%)$ & $29(47 \%)$ \\
Psychiatric disorder & $11(4 \%)$ & $2(3 \%)$ \\
Heart disease & $5(2 \%)$ & $18(29 \%)$ \\
Diabetes mellitus & $5(2 \%)$ & $10(16 \%)$ \\
Lumbar spinal stenosis & $5(2 \%)$ & $7(11 \%)$ \\
Ankylosing spondylitis/ & $4(1 \%)$ & $4(6 \%)$ \\
$\quad$ rheumatoid arthritis & & \\
Cervical spondylosis & $3(1 \%)$ & $5(8 \%)$ \\
Chronic obstructive & $3(1 \%)$ & $7(11 \%)$ \\
$\quad$ pulmonary disease & $2(1 \%)$ & $11(17 \%)$ \\
Osteoarthritis & $1(1 \%)$ & $1(2 \%)$ \\
Kidney calculus & &
\end{tabular}

$98(27 \%)$, from gunshot wounds in 57 $(16 \%)$, from sports or diving incidents in 39 $(11 \%)$, and from other causes in $36(10 \%)$.

Associated injuries occurred at the time of the SCI in $202(56 \%)$ patients. Patients had a mean of $0.9 \pm 1.0$ associated injuries each. Specific types of associated injuries are listed in Table II. A total of 197 patients (55\%) underwent surgical spinal fusion. Artificial mechanical ventilation was required following injury in $71(20 \%)$ patients.

The mean acute length of stay was $30.8 \pm 25.5$ days, and the mean rehabilitation length of stay was $73.7 \pm 32.4$. Nearly all of the patients (337 or $94 \%$ ) had at least one medical complication during the acute or rehabilitation hospitalization, with an average of $2.5 \pm 1.6$ complications per patient. Specific complications are listed in Table III. At discharge, 75 (21\%) patients had normal continent spontaneous bladders, while 194 (54\%) patients were using intermittent catheterization, $21(6 \%)$ external catheters, and 68 (19\%) indwelling urethral catheters.

The number of patients discharged home was $324(91 \%)$, to nursing homes $24(6 \%)$, and to other locations $10(3 \%)$.

\section{Comparison of older and younger patients}

Differences between the older and younger patient groups are shown in Table IV.
Table II Associated injuries

\begin{tabular}{lrr}
\hline Injury & Younger & \multicolumn{1}{c}{ Older } \\
& $\mathrm{N}=296$ & $\mathrm{~N}=62$ \\
\hline Loss of consciousness & $124(42 \%)$ & $22(35 \%)$ \\
Long bone fracture & $80(27 \%)$ & $15(24 \%)$ \\
$\begin{array}{l}\text { Pneumothorax/ } \\
\text { hemothorax }\end{array}$ & $66(22 \%)$ & $9(15 \%)$ \\
Brachial plexus injury & $5(2 \%)$ & 0 \\
\hline
\end{tabular}

Table III Medical complications

\begin{tabular}{|c|c|c|}
\hline Condition & $\begin{array}{l}\text { Younger } \\
\mathrm{N}=296\end{array}$ & $\begin{array}{l}\text { Older } \\
\mathrm{N}=62\end{array}$ \\
\hline $\begin{array}{l}\text { Urinary tract } \\
\text { infection }\end{array}$ & $259(88 \%)$ & $59(95 \%)$ \\
\hline Pressure sore & $121(41 \%)$ & $30(48 \%)$ \\
\hline Severe spasticity & $79(27 \%)$ & $9(15 \%)$ \\
\hline $\begin{array}{l}\text { Unexplained chills/ } \\
\text { fever }\end{array}$ & $47(16 \%)$ & $7(11 \%)$ \\
\hline Atelectasis & $42(14 \%)$ & $12(19 \%)$ \\
\hline Pneumonia & $39(13 \%)$ & $10(16 \%)$ \\
\hline $\begin{array}{l}\text { Deep venous } \\
\text { thrombosis }\end{array}$ & $33(11 \%)$ & $7(11 \%)$ \\
\hline Ventilatory failure & $33(11 \%)$ & $9(15 \%)$ \\
\hline Autonomic dysreflexia & $28(9 \%)$ & $2(3 \%)$ \\
\hline Aspiration & $14(5 \%)$ & $2(3 \%)$ \\
\hline $\begin{array}{l}\text { Cardiopulmonary } \\
\text { arrest }\end{array}$ & $12(4 \%)$ & $8(13 \%)$ \\
\hline Pulmonary embolism & $9(3 \%)$ & $3(5 \%)$ \\
\hline $\begin{array}{l}\text { Gastrointestinal } \\
\text { hemorrhage }\end{array}$ & $7(2 \%)$ & $1(2 \%)$ \\
\hline Epididymitis & $6(2 \%)$ & 0 \\
\hline Severe contracture & $5(2 \%)$ & 0 \\
\hline $\begin{array}{l}\text { Heterotopic } \\
\text { ossification }\end{array}$ & $4(1 \%)$ & $1(2 \%)$ \\
\hline $\begin{array}{l}\text { Operative wound } \\
\text { infection }\end{array}$ & $3(1 \%)$ & $1(2 \%)$ \\
\hline Motor power loss & $2(1 \%)$ & 0 \\
\hline Acquired scoliosis & $1(1 \%)$ & 0 \\
\hline Kidney calculus & $1(1 \%)$ & 0 \\
\hline
\end{tabular}

Compared to the younger patients, the older SCI patient group had a significantly greater proportion of females, preexisting medical conditions (and average numbers of preexisting conditions), incomplete quadriplegic patients, persons whose injuries resulted from falls, and associated injuries (but not mean number of associated injuries). Older patients were less likely to undergo surgical spinal fusion than were 
Table IV Comparisons between younger and older spinal cord injury patients

\begin{tabular}{|c|c|c|c|}
\hline Patient details & $\begin{array}{l}\text { Younger } \\
\mathrm{N}=296\end{array}$ & $\begin{array}{l}\text { Older } \\
\mathrm{N}=62\end{array}$ & Significance \\
\hline \multirow{4}{*}{$\begin{array}{l}\text { Gender male } \\
\text { female } \\
\text { Preexisting conditions } \\
\text { mean }\end{array}$} & $83 \%$ & $71 \%$ & \\
\hline & $17 \%$ & $29 \%$ & $p<0.05$ \\
\hline & $43 \%$ & $87 \%$ & $p<0.0001$ \\
\hline & 0.6 & 1.9 & $p<0.0001$ \\
\hline \multicolumn{4}{|l|}{$\begin{array}{l}\text { Neurological class } \\
\text { complete }\end{array}$} \\
\hline $\begin{array}{l}\text { incomplete } \\
\text { quadriplegia }\end{array}$ & $35 \%$ & $63 \%$ & \\
\hline $\begin{array}{l}\text { complete } \\
\text { paraplegia }\end{array}$ & $24 \%$ & $13 \%$ & \\
\hline $\begin{array}{l}\text { incomplete } \\
\text { paraplegia }\end{array}$ & $21 \%$ & $16 \%$ & $p<0.001$ \\
\hline \multicolumn{4}{|l|}{ Etiology } \\
\hline road-traffic & $41 \%$ & $34 \%$ & \\
\hline falls & $22 \%$ & $53 \%$ & \\
\hline gunshot wound & $20 \%$ & 0 & \\
\hline sports/diving & $13 \%$ & $2 \%$ & \\
\hline other & $4 \%$ & $11 \%$ & $p<0.0001$ \\
\hline Associated injury & $41 \%$ & $55 \%$ & $p=0.05$ \\
\hline mean & 0.9 & 0.7 & $p=\mathrm{NS}$ \\
\hline Surgical fusion & $58 \%$ & $40 \%$ & $p<0.05$ \\
\hline Ventilator use & $19 \%$ & $22 \%$ & $p=\mathrm{NS}$ \\
\hline Mean acute stay, days & 26.1 & 22.7 & $p=\mathrm{NS}$ \\
\hline Mean rehab stay, days & 75.2 & 66.5 & $p<0.05$ \\
\hline Medical complications & $93 \%$ & $98 \%$ & $p=\mathrm{NS}$ \\
\hline mean & 2.5 & 2.6 & $p=\mathrm{NS}$ \\
\hline \multicolumn{4}{|l|}{ Bladder management } \\
\hline normal & $19 \%$ & $29 \%$ & \\
\hline intermittent & $58 \%$ & $35 \%$ & \\
\hline external & $6 \%$ & $5 \%$ & \\
\hline indwelling & $17 \%$ & $31 \%$ & $p<0.01$ \\
\hline \multicolumn{4}{|l|}{ Disposition } \\
\hline home & $93 \%$ & $78 \%$ & \\
\hline nursing home & $4 \%$ & $19 \%$ & \\
\hline other & $3 \%$ & $3 \%$ & $p<0.0001$ \\
\hline
\end{tabular}

younger patients. There were no differences between groups in ventilator use or medical complications.

Although there was no difference between age groups in mean acute length of stay, there was a difference in rehabilitation length of stay; younger persons stayed an average of 9 days longer for rehabilitation than did older patients. Older adults were more likely to be discharged with indwelling urethral catheters than were younger adults. There was also a difference between age groups with respect to discharge location; older patients were significantly more likely to have been discharged to nursing homes than were younger patients.

Factors associated with outcome for the entire sample

A multivariate analysis of variance was performed to determine those factors which were associated with acute length of stay. Only female gender $(p<0.01)$, associated injury $(p<0.01)$, and mechanical ventilator use $(p<0.0001)$ were associated with 
longer acute lengths of stay; age, preexisting condition, substance abuse history, neurological class, etiology, surgical spinal fusion, and occurrence of medical complications were unrelated to acute length of stay.

A separate multivariate analysis of variance was performed to determine those factors which were associated with rehabilitation length of stay. Factors which were associated with longer rehabilitation periods included the presence of a preexisting condition $(p<0.01)$, neurological class $(p<$ $0.0001)$, occurrence of associated injury $(p<0.05)$, surgical fusion $(p<0.001)$, mechanical ventilator use $(p<0.01)$, and occurrence of medical complication during hospitalization $(p<0.0001)$. Age, gender, substance abuse history, and injury etiology were unrelated to rehabilitation length of stay.

Factors associated with discharge location included only age, preexisting medical condition, neurological class, and etiology. Compared to patients who were discharged to nursing homes from rehabilitation, patients who were discharged home were significantly younger $(p<0.01)$, and were significantly more likely to have preexisting medical conditions $(p<0.01)$, incomplete paraplegia $(p<0.01)$, and a road traffic accident etiology $(p<0.01)$. Gender, substance abuse history, occurrence of associated injury, surgical spinal fusion, ventilator use, and occurrence of a medical complication were unrelated to discharge location.

Patients who were using intermittent catheterization were significantly more likely to be discharged home $(p<0.001)$.

Finally, patients who were discharged home had a significantly shorter acute length of stay than did those who were discharged to nursing homes or elsewhere (29.2 days vs 47.5 days; $p<0.05)$. There was no statistical relationship between rehabilitation length of stay and discharge location.

\section{Factors associated with outcomes in older SCI patients}

Separate analyses were performed of data on the older SCI patients to determine which of the demographic and injury variables were related to outcome in that patient group. Among the 62 older SCI patients, only female gender (41 days vs 29 days; $p<0.05)$ and ventilator use (45 days vs 28 days; $p<0.05$ ) were associated with acute length of stay. None of the demographic or injury characteristics was associated with rehabilitation length of stay.

The only demographic or injury factor associated with discharge location was neurological class; patients with complete paraplegia or quadriplegia were discharged more frequently to nursing homes $(38 \%$ vs $14 \% ; p<0.05)$ than with incomplete paraplegia or quadriplegia. No other statistical relationships were noted between preinjury or injury variables, including substance abuse history and surgical fusion history, and discharge destination.

Among the older patients, those who were using intermittent catheterization at discharge were significantly more likely to be discharged home than were those who were using indwelling catheters $(42 \%$ vs $20 \% ; p<0.01)$.

The older adults who were discharged to nursing homes stayed significantly longer in acute care than did those who went home (47.6 vs 27.7 days, $p<0.01$ ). However, there were no differences in rehabilitation stay between those who were discharged home and those who were not.

\section{Discussion}

Although many aspects of the presentation, course, and care of older spinal cord injury (SCI) individuals are similar to those of younger patients, there are several unique features of the older group. The findings of this study confirm those of prior reports that older patients are more likely to be female, to have injuries resulting from falls, and to have incomplete quadriplegia. ${ }^{13-15}$ In the present study, there were no major differences between age groups with respect to incidence of complications or requirement for mechanical ventilation, but there were notable differences in the frequency, pattern, and types of preexisting medical conditions of each group. This finding underscores the multiplicity of medical issues that face the older SCI patient. The similarity in the frequency of complications is in contrast 
to the observation by Stover and associates ${ }^{14}$ that older adults were more likely to experience medical illnesses such as pneumonia, gastrointestinal hemorrhage, pulmonary embolus, and renal stones.

The analysis of variance, using data from the entire sample of 358 patients, failed to show an independent relationship between age and length of stay. This finding suggested that the influence of age on acute and rehabilitation length of stay was minimal, and that other factors had a more important influence on the duration of hospitalization. Only level and completeness of injury appeared to have a significant impact on the course and outcome of these patients, according to the analysis. While older adults had a slightly shorter rehabilitation stay, this probably occurred because there were more patients with incomplete spinal cord injuries in that group, requiring less prolonged therapy programs. The shorter stays of the older group did not appear to have resulted from an expectation of reduced levels of function; there was no relationship between substance abuse history and discharge destination, nor between rehabilitation length of stay and discharge destination.

There were significant differences between older and younger patients with respect to urinary bladder management outcomes. Older patients were nearly twice as likely to have been discharged with indwelling urethral catheters as were the younger patients. Similar findings have been reported in a previous study. ${ }^{27}$ The implications of these observations are important, as is reflected by the finding that patients with indwelling catheters were significantly more likely to have been discharged to nursing homes than were those on intermittent catheterization.

One of the most important considerations during the care of the older SCI patient is placement after discharge from the hospital. It is generally recognized that more than $90 \%$ of SCI patients return home after SCI rehabilitation. ${ }^{21,23}$ However, the likelihood of home discharge is significantly smaller in older adults ( $78 \%$ in the present study). This percentage is comparable to that quoted by Watson, ${ }^{13}$ Stover and associates, ${ }^{14}$ and Subbarao and associates, ${ }^{17}$ and probably results from the lack of available social supports, the complexity of their dependency needs, and their concomitant medical problems. Stover and associates, ${ }^{17}$ for example, reported that the incidence of discharge to nursing homes after initial hospitalization of older SCI patients was 22.7 times the incidence in younger adults.

When other factors were controlled for, advancing age was a predictive factor only for nursing home discharge and not for length of acute and rehabilitation stay. Acute length of stay was significantly related only to occurrence of associated injury and ventilator dependency; management of these problems probably outweighed age in importance. Longer rehabilitation stays occurred for those with preexisting conditions, associated injury, mechanical ventilator use, and medical complications. Each of these factors has an impact on medical stability, exercise tolerance, and ability to participate in a rehabilitation training program. Rehabilitation length of stay was also related to neurological class; patients with complete injuries and those with quadriplegia stayed longer in rehabilitation. Once again, age alone was not an independent mediating factor in the determination of length of stay.

Among older patients, patients with complete injuries were the most likely to have been discharged to nursing homes, approaching 3 times as many nursing home discharges as in the patients with incomplete injuries. This is clearly a reflection of the severity of their disability and the lack of available assistance in the home.

In general, older adults who sustain a spinal cord injury have particular medical, functional, and social issues that require specialized management. Despite a greater frequency, severity, and complexity of accompanying problems, and a greater likelihood of discharge to nursing homes, older adults are able to achieve favorable outcomes from comprehensive acute SCI care and rehabilitation.

\section{Acknowledgements}

This work was supported in part by Grant G008535129 (The Midwest Regional Spinal Cord Injury Care System) and H133B80007 
(The Medical Rehabilitation Research and Training Center in Prevention and Treatment of Secondary Complications in Spinal Cord Injury), National Institute of Disability and Reha- bilitation Research, US Department of Education, Washington, DC, USA, and by the Rehabilitation Institute of Chicago, Chicago, Illinois, USA.

\section{References}

1 US Bureau of the Census (1984) Projections of the population of the United States, by Age, Sex, and Race, 1983 to 2080. Current Population Reports. Series P-25, No. 952. US Government Printing Office, Washington DC.

2 National Safety Council (1986) Accident Facts. 1986 ed. Chicago, Illinois.

3 National Center for Health Statistics (1986) 1986 Summary: National Hospital Discharge Survey. Number 145. Hyattsville, Maryland.

4 Mueller MS, Gibson RM (1976) Age difference in health care spending. Social Security Bulletin 36: 18.

5 Companion EW, Mulley AG, Goldstein RL et al (1981) Medical intensive care for the elderly: a study of current use, costs, and outcomes. JAMA 246: 2052-2056.

6 Gerson LW, Skvarch L (1982) Emergency medical service utilization by the elderly. Ann Emerg Med 11: 610-612.

7 Snipes GE (1982) Accidents in the elderly. Am Fam Physician 26: 117-122.

8 Baker SP, O'Neill B, Karpf RS (1984) The Injury Fact Book. Lexington, Kentucky: Lexington Books.

9 Champion HR, Copes WS, Buyer D, Flanagan ME, Bain L, Sacco WJ (1989) Major trauma in geriatric patients. Am J Public Health 79: 1278-1282.

10 Finelli FC, Jonsson J, Champion HR et al (1989) A case control study of major trauma in geriatric patients. J Trauma 29: 54-548.

11 Kalsbeek WD, McLaurin RL, Harris BSH, Miller JD (1980) The national head and spinal injury survey: major findings. J Neurosurg 53: S19-S31.

12 Bracken MB, Freeman DH, Hellenbrand K (1981) Incidence of acute traumatic spinal cord injury in the United States, 1970-1977. Am J Epidemiol 113: 615-622.

13 Watson N (1976) Pattern of spinal cord injury in the elderly. Paraplegia 14: 36-40.

14 Stover SL, Kartus PL, Rutt RD, Fine PR, Devivo MJ (1987) Outcomes of the older patient with spinal cord injury. Arch Phys Med Rehabil 68: 672.

15 Yarkony GM, Roth EJ, Heinemann AW, Lovell LL (1988) Spinal cord injury rehabilitation outcome: the impact of age. J Clin Epidemiol 41: 173-177.

16 Eisenberg MG, Tierney DO (1985) changing demographic profile of the spinal cord injury population: implication for health care support systems. Paraplegia 23: 335-343.

17 Subarrao JV. Nemchausky BA, Niekelski JJ, Fruin RC, Gratzer M (1987) Spinal cord dysfunction in older patients-rehabilitation outcomes. J Am Paraplegia Soc 10: 30-35.

18 Kurtzke JF (1975) Epidemiology of spinal cord injury. Exp Neurol 48 (3, 2): 163-236.

19 Mesard L, Carmody A, Mannarino E, Ruge D (1978) Survival after spinal cord trauma: a life table analysis. Arch Neurol 35: 78-83.

20 Kraus JF, Franti CE, Borhani NO, Riggins RS (1979) Survival with an spinal-cord injury. J Chron Dis 32: 269-283.

21 Young JS, Burns PE, Bowen AM, McCutchen R (1982) Spinal Cord Injury-Statistics: Experience of the Regional Spinal Cord Injury Systems. Good Samaritan Medical Center Press, Phoenix, Arizona.

22 Geisler WO, Jousse AT, Wynne-Jones M et al (1983) Survival in traumatic spinal cord injury. Paraplegia 21: $364-373$.

23 Stover SL, Fine PR (1986) Spinal Cord Injury: The Facts and Figures. The University of Alabama Press, Birmingham, Alabama.

24 Daverat P, Gagnon M, Dartigues JF, Mazaux JM, Barat M (1989) Initial factors predicting survival in patients with a spinal cord injury. J Neurol Neurosurg Psychiatry 52: 403-406.

25 Murray PK, Nuller J, Clark GS (1982) Functional prognosis in the elderly spinal cord injured. Arch Phys Med Rehabil 63: 513-514.

26 Hooker EZ (1986) Problems of veterans spinal cord injured after age 55: nursing implications. J Neurosci Nurs 18: $188-194$.

27 Madersbacher G, Oberwalder M (1987) The elderly para- and tetraplegic: special aspects of urological care. Paraplegia 25: 318-323. 